\title{
La estructura de dominación mundial y la búsqueda del modelo propio*
}

\section{Parra Luzardo, Gastón}

\section{Introducción necesaria}

Confieso sentirme orgulloso y conmovido por habérseme conferido el título de doctor Honoris Causa que tanto me honra; y estimulado - a la vez-por el extraordinario reconocimiento. Expreso al decano, José Antonio Chirinos, a los integrantes de la Asamblea de la Facultad de Ciencias Económicas y Sociales, así como al Rector, Neuro Villalobos y distinguidos miembros del Consejo Universitario de esta ilustre universidad mi agradecimiento, por tan honrosa distinción acordada por unanimidad; también para el maestro latinoamericano doctor Bernardo Kliksberg. Lo acepto con la mayor modestia, sin vanidad de vanidades, convencido de mi profunda vocación por la enseñanza y la investigación, a las cuales he dedicado la mayor parte de mi vida, de manera abnegada y comprometida con los más altos y nobles ideales nacionales. Lo realizado ha tenido como norte el amor a lo realmente humano, a la permanente búsqueda de la verdad, la libertad, la justicia y dignidad de todos los hombres, siempre con el deseo de procurar el bienestar de la sociedad. Mantener una posición consecuente, ser coherente y sincero han constituido aspectos primordiales en mi existencia.

La Facultad de Ciencias Económicas y Sociales, fue creada por el Consejo Académico de esta Casa de Estudios Superiores, en su sesión extraordinaria del 30 de septiembre de 1958 , y presidido por el ilustre rector, Antonio Borjas Romero, después del análisis al informe presentado por los miembros de la comisión nombrada para elaborar el proyecto de organización y funcionamiento de la facultad, de la cual, importa recordar en estos momentos, formaron parte los doctores Jesús Morillo González, universitario a carta cabal, probo y verdadero impulsor de la necesidad de los estudios de las Ciencias Económicas en el Zulia, y a quien se le

* Discurso pronunciado por el Dr. Gastón Parra Luzardo, en el acto en que La Universidad del Zulia le confirió el Título de Doctor Honoris Causa. Maracaibo, Venezuela, 11 de junio de 1999. Posteriormente (el 25 de julio) fue electo miembro de la Asamblea Nacional Constituyente responsable de elaborar la Constitución que regirá los destinos del país a partir del próximo siglo. 
confirió el Doctorado Honoris Causa; Ernesto González Araujo y Luis C. Hueck. Me enaltece haber participado, como estudiante de secundaria, en el primer comité pro-fundación de la facultad, acompañado de Alberto La Roche, Euro Wilheln, Douglas Bravo, All Enmanuel, Luis Andrade y Abdénago Arrieta. También impulsaron esa idea: Omar Baralt, presidente para ese entonces, del Centro de Estudiantes de Derecho; Leopoldo Guillermo Díaz, José Alvarado, Brinolío Beltrán, y profesores como los doctores Hercolino Adrianza Alvarez y José Ortín Rodríguez. Tuve la suerte de ser director de la Escuela de Economia y decano de esta facultad. Muchas satisfacciones me ha brindado esta facultad, a la cual está arraigada mi existencia. Recuerdos perennes lo constituyen quienes han sido mis discípulos, que en varias oportunidades me han distinguido como epónimo o padrino de sus promociones, así como haber compartido a diario con colegas profesores y trabajadores. Recuerdo imborrable lo constituyen mis compañeros integrantes de la primera promoción de economistas egresada en febrero de 1964, de esta universidad.

Es por esa y otras razones que me siento abrumado. Esta distinción, que recibo con honra y tanto aprecio, me obliga a continuar defendiendo con honradez mis convicciones, aunque con modestia y sin soberbia; a continuar sin desmayo en la lucha por procurar una sociedad genuinamente democrática, con gobier- nos honrados y eficientes, capaces de enfrentar y no doblegarse ante los poderosos de la Tierra. En nombre de esos nobles e irrenunciables ideales, espero con firmeza no defraudar a quienes han depositado tanta confianza en este profesor que jamás dejará de serlo. A todos invito, al invocar a Ernesto Sábato, a tener presente que "Sólo quienes sean capaces de encarnar la utopia, serấn aptos para el combate decisivo: el de recuperar cuanto de humanidad hayamos perdido".

\section{La ciencia económica, ¿en beneficio de quién?}

En ese orden de ideas, importa preguntarnos: ¿Qué sistema de pensamiento permitirá poner de pie lo que Eduardo Galeano ha calificado como "La Escuela del Mundo al revés"? ${ }^{1}$.

La economía política es una ciencia eminentemente social, que tiene como objetivo primordial ver las relaciones económicas como relaciones entre hombres y mujeres de carne y hueso. No se trata de cosas, sino de relaciones sociales. Por ello, no es posible admitir la neutralidad de los científicos sociales, a la que tanto aluden los poderes imperiales. Las ciencias sociales no deben ser acientíficas, su objetivo es elevar la consciencia, es descubrir las causas, el modo de funcionamiento y las consecuencias.

Debemos confesar que las doctrinas económicas, vulgarizadas, procla-

1 Cf. Eduardo Galeano: "Patas arribas. La escuela del mundo al revés" Editorial Siglo XXI, México. 1998. 
man el efecto benefactor del libre juego del objetivo de la ganancia. El mercado se concibe como un fin y no como un me. dio, para lograr el bienestar. Se hace énfasis en un mercado perfectamente competitivo que garantiza la asignación óptima de los recursos entre diversos usos posibles. "Se describió la economía como el estudio de la conducta humana, como una relación entre fines y medios escasos a los que puede darse diversos usos. La ortodoxia basada en esta concepción se derrumbó durante la gran depresión, cuando la persecución de las ganancias no logró hacer uso de una gran parte de los recursos con no importa qué finalidad"2. Por fortuna, comienza a recorrerse el largo y difícil camino que va de una ciencia social acartonada, formalista, acrítica y aún apologética, hacia una ciencia social que a través del estudio sistemático de la realidad, intente descubrir las causas del atraso y procure las transformaciones necesarias.

Permítanme recordar en este auditorio, escenario de grandes debates, en torno de estas ideas, cuán lejos, cuán distante y plena de obstáculos -sembrados por quienes dominan el mundo-, está de cumplirse, llevarse a la realidad, a pleno funcionamiento, la simple definición de la ciencia económica: "La economía política - o economía social- es la ciencia de las leyes sociales que rigen la producción y la distribución de los medios materiales que sirven para satisfacer las necesidades humanas" ${ }^{3}$, es decir, alimentación, salud, educación, vivienda, vestido, seguridad y recreación sana para la población.

¿Por qué no ha sido posible planificar y desarrollar una estrategia integral para lograr ese noble propósito? $Y$ en cambio, imperan las desigualdades, las injusticias, la exclusión social, a la que con tanta fuerza y rigor científico se ha referido en sus obras quien hoy me acompaña, al recibir también el título de Doctor Honoris Causa de esta casa de estudios, doctor Bernardo Kliksberg.

\section{La estructura de dominación mundial}

En realidad, el mapa geopolítico internacional está conformado por tres grandes bloques que confluyen en un centro de dominio mundial, desde donde se planifica, desarrolla, aplica y ejerce la estrategia económica, política, social, tecnológica, militar, cultural y comunicacional, cónsona con intereses muy particulares, que son la razón de ser del sistema capitalista.

Ese monopoder mundial está integrado por los paises que conforman el grupo de los siete (G-7) y que lideran, fundamentalmente, Estados Unidos, Japón y Alemania. El G-7 reúne a los principales países industriales que ejercen una poderosa influencia en el mundo. El G-7 ejerce el dominio del comercio mundial, cuenta con los mayores recursos financieros, controla el mercado internacional de los servicios, posee una poderosa 
fuerza militar y domina los medios de comunicación. La investigación y el desarrollo están bajo sus dominios absolutos.

Para el desarrollo de todas esas actividades, producto de la estrategia centralizada, el G-7 cuenta con las empresas transnacionales que constituyen la forma avanzada de organización empresarial del sistema capitalista. Asimismo, para el fiel cumplimiento de la estrategia concebida, tiene a su disposición instituciones y organismos internacionales, tales como el Fondo Monetario Internacional (FMI), el Banco Mundial (BM), la Organización Mundial del Comercio (OMC), la Organización del Tratado del Atlántico Norte (OTAN), entre otras.

Esta estructura económica y política internacional constituye para otros países y, especificamente, para la consecución de una genuina estrategia, no transnacionalizada y dependiente, una limitación, al impedir en la práctica el desarrollo de auténticas políticas nacionales.

Por esta razón, resulta conveniente conocer esa realidad, a los fines de elegir el camino más adecuado.

La creciente internacionalización ha provocado profundos cambios en el proceso de reestructuración mundial. Al respecto, conviene destacar la creciente sustitución de las otroras industrias dinámicas que han sido reemplazadas por las actividades de punta, tales como la biotecnología, la microelectrónica, la robótica, la ingeniería genética, as l como la sustitución de una gran mayoría de bienes primarios por sucedáneos. Todo eso incide, sin duda alguna, en que el proceso de acumulación capitalista esté en función de los crecientes avances tecnológi$\cos y$, por ende, conduce hacia una cada vez menor demanda de bienes primarios, así como hacia una disminución progresiva del uso de la fuerza de trabajo. Estos hechos tienen y tendrán efectos adversos para la economia latinoamericana $y$, especificamente, para Venezuela, y cada vez se agudizarán, a menos que oportunamente, con una estrategia propia, se actúe sobre el particular y se formulen salidas que enfrenten esa situación.

Otro de los cambios que amerita suma atención es el que concierne a la creciente sustitución, en el proceso económico internacional, de la economía real por la economía símbólica-monetaria. Todo parece indicar que la producción de bienes y senvicios dejó de ser el objetivo esencial de la economía para abrirle mayores espacios a la venta, compra y multiplicación de los activos financieros.

Todo eso indica el poder que actualmente tiene la economía simbólica o monetaria y, por tanto, los serios riesgos que de ello derivan.

En la dinámica del proceso de desarrollo del sistema capitalista, hoy en su fase globalizadora, se obsena la ineludible tendencia hacia una cada vez mayor concentración de la actividad económica, pero con ciertos grados de flexibilización de la centralización.

$Y$, por último, un aspecto crucial lo constituye el hecho de que -al decir de algunos- el Estado-Nación dejó de ser la unidad predominante para la planificación, desarrollo y aplicación de las políticas económicas y sociales. Hoy, en la economía transnacionalizada, se afirma que la política económica emerge de varias unidades, a saber, el Estado, sobre todo en los países más poderosos, los bloques económicos de poder mundial, la 
economía financiera internacional y las corporaciones internacionales.

Pero es innegable que esas formas del "Poder Global", de la estructura económico-política mundial, de los monopolios transnacionalizados, representan una seria limitación para la búsqueda de genuinas políticas nacionales. En ese sentido, conviene subrayar que el propio Adam Smith, en su libro "La investigación sobre la naturaleza y causas de la riqueza de las naciones", mostró su hostilidad hacia esas formas del poder, y afirmó, con razón, que "tales compañías (corporaciones) económicas son siempre nocivas y perjudiciales al país en que se establecen, $y$ en extremo ruinosas para los pueblos que tuvieron la desventura de caer bajo su gobierno". Pero ocurre que los apologistas del neoliberalismo, en nombre del libre mercado, de la teologia del mercado, olvidan ex profeso el pensamiento del maestro Adam Smith, manipulan con el concepto del liberalismo $o$, en todo caso, prefieren eludirlo o ignorarlo.

Ante la realidad del monopoder mundial, corresponde interrogarse: $¿ E s$ eso lo que conviene a la humanidad? ¿Acaso favorece eludirla? ¿Cómo defender la especificidad de los paises? En la búsqueda de auténticas y legítimas respuestas a esas interrogantes, es pertinente dedicarse con vocación, con ética, con inquietud social, responsabilidad y honradez intelectual, al análisis riguroso que asunto de tanta importancia requiere.
Lo que sí sería imperdonable es adoptar la posición del conformista. "Más vale errar que dormir", afirmó el maestro Simón Rodríguez. ¿Cómo actuar frente a ese proceso de globalización transnacionalizado, expansionista a expensas de la soberania y la libertad de los pueblos, clases sociales y personas, hegemonista, avasallador, que procura y verdaderamente logra convertir a los Estados nacionales en fincas, en simples piezas del engranaje mundial, en países globalizados?

La llamada globalización representa la fase actual del modo de producción existente que, entre otras cosas, expresa la liberalización desigual y parcial de las fuerzas del mercado, limita la capacidad de acción de los Estados nacionales y fortalece la dependencia de carácter estructural. Con la globalización se pretende consolidar el monopoder mundial.

Los exégetas de ese proceso creen, firmemente, que esa es la forma de organización perfecta y única. Es el fundamentalismo desbordado. Es el pensamiento único. Es la ideología de la globalidad. Otros piensan en la posibilidad de aplicar ciertos remiendos, algunos ajustes y admitir, por supuesto, sus defectos.

A este respecto, Keynes advirtió que "...cuando se comprendiese la operación del sistema capitalista, su gran poder productivo se utilizaría para crear condiciones en las que prefeririamos dedicar nuestras energias sobrantes a la realización de fines económicos"4. Lo que ya no es posible, razonó Joan Robinson, es 
“...defenderlo al estilo neoclásico, como un mecanismo delicado y autorregulador, al que lo único que hay que hacer es dejarlo actuar por sí mismo para que produzca la mayor satisfacción para todos"5. Se justifica al sistema imperial $y$, por supuesto, dominante, por razones políticas, y hasta se aduce que la democracia, tal como existe hoy, no podría desarrollarse en otro sistema. Pero nos preguntamos: ¿cuántos desequilibrios sociales está en capacidad de dulcificar la democracia? ¿Cómo justificar, en nombre de la democracia, que el 85 por ciento de la población venezolana viva en estado de pobre$\mathrm{za}$, que el 40 por ciento esté sumergida en la pobreza extrema, y un 15 por ciento viva en pobreza atroz? ¿Hasta dónde soportar tanta injusticia humana? ¿Cómo entender que América Latina esté considerada internacionalmente con los más elevados niveles de desigualdad? ¿Cómo avalar la presencia de la metástasis de la desigualdad social?

Todo esto exige una seria reflexión en torno a la obligante necesidad de revisar a fondo el cumplimiento de la democracia y sus actores.

Otros, en cambio, prefieren adoptar la postura rigurosa que Schumpeter hizo derivar de Carlos Marx: "El sistema es cruel, injusto, turbulento, pero nos proporciona los bienes necesarios" .

En nuestro criterio, en verdad nos encontramos en una etapa de plena incertidumbre y de graves riesgos, pero al mismo tiempo, de promesas y posibilida- des. No perdamos la esperanza, la real confianza de buscar, de abrir caminos, alternativas, quizás inéditas, preñadas de humanismo, condición de la cual -ciertamente-carece el modo de organización predominante.

\section{3. ¿Cuál es el camino?}

En ese orden de ideas, conviene subrayar que la gran interrogante latinoamericana, que debería ser el corazón de una profunda consideración, es la de planificar, desarrollar y ejecutar una estrategia no subordinada al poder mundial; definir e impulsar su propia alternativa, abrir caminos con respeto y dignidad, tomando en cuenta, por supuesto, el diagnóstico económico-social de la región, así como también, las ligazones con la actual coyuntura internacional, sobre todo, si asumimos que América Latina, por múltiples factores, está articulada al sistema capitalista, modo de producción imperante que hoy día, con la llamada globalización transnacionalizada, pretende regir, dentro del mayor fundamentalismo, los destinos de los países del orbe.

Históricamente sería imperdonable que mientras la crisis del modelo de acumulación del propio sistema capitalista lo hallevado a la búsqueda de nuevas alternativas $y$, por tanto, a impulsar las transformaciones necesarias, con el fin de mantener y acrecentar, a como de lugar, su poderío mundial con el reino de las injusticias sociales, los países de América

6 Ibid. 
Latina procuren, una vez más, ponerse a tono con los nuevos objetivos del sisterna globalizado transnacional, y pasar a formarparte, como elemento pasivo y de escasa fuerza, de la nueva estructura del capitalismo mundial; con lo cual se estaría cometiendo, más que un grave error, un crimen de lesa patria. Por el contrario, debe auspiciarse la urgente necesidad de provocar transformaciones esenciales, indispensables para corregir los grandes males que aquejan a la sociedad latinoamericana. Pero esas transformaciones no pueden sustentarse o confiarse a la simple espontaneidad del mercado.

En nuestro criterio, entre los desafíos de América Latina y el Caribe debe estar el impulsar un verdadero desarrollo regional, el lograr una auténtica integración y cooperación económica, fomentando condiciones ventajosas y favorables sobre la base de sus recursos internos, sus potencialidades, experiencias y esfuerzos $y$, por supuesto, concebirlo como un proyecto político de negociación frente a los otros bloques regionales de poder. No debemos permitir que la orientación de ese proceso se nos arrebate una vez más. Ese proceso deberá estar al servicio de los legítimos intereses de los paises latinoamericanos y caribeños. Es la hora de elaborar y desarrollar esa estrategia en el marco de las alternativas de transformación que requieren nuestros países.

\section{La estrategia económica para Venezuela}

Es innegable que existe la necesidad de provocar transformaciones profundas en la forma de inserción con la economia mundial. Pero ello requiere de una estrategia que surja soberanamente, no subordinada. La estrategia económica para Venezuela debe ser concebida para el presente y para el futuro; debe ser de largo plazo, teniendo en cuenta, por supuesto, el mediano y corto plazos; no puede circunscribirse a lo meramente coyuntural, inmediatista o convencional, dado que la crisis económico-social del pais es de carácter estructural. Para que la estrategia económica de Venezuela pueda tener éxito, se requiere que la misma esté sustentada sobre bases firmes, en pleno conocimiento de la realidad nacional, que permita acometer las acciones apropiadas para la búsqueda del genuino desarrollo integral, orgánico y sostenido, en beneficio de la población. Para desarrollar y aplicar una auténtica estrategia económica, es de vital importancia develar los problemas estructurales que caracterizan a la economía venezolana. Estudiar, analizar e interpretar -en su exacta dimensión- los rasgos estructurales de la economia, tal cual lo ha hecho con rigor cientifico el maestro D.F. Maza Zavala, tales como la heterogeneidad estructural, la monopolización, la dependencia y vuinerabilidad, la desigual distribución del ingreso, los desequilibrios sectoriales y regionales prevalecientes en el pais, conjuntamente con el contexto internacional, resulta indispensable para la aplicación de políticas cónsonas con esa realidad tan compleja y plena de adversidades. Entender que "...el problema no es más Estado o menos Estado, sino mejor Estado; y el mercado no es fin en sí mismo, sino medio para obtener mejores metas sociales", es de suma importancia, si es que de verdad se desean los cam- 
bios necesarios para impulsar el desarrollo. Saber cómo y para qué actuar es fundamental. Sería un gravísimo error instrumentar una estrategia alejada de esa realidad, ello puede conducir hacia resultados totalmente adversos a los objetivos prioritarios de una genuina estrategia económica, social y política, como lo es satisfacer las necesidades esenciales de la población.

Por supuesto, no se nos escapa la complejidad de los problemas existentes $y$ las presiones que ejercen el monopoder mundial y los monopolios transnacionalizados, para que nada cambie y todo continúe igual, es decir, el camino sin obstáculos. Pero Venezuela espera por el cambio real, por una nueva organización que impulse el desarrollo y funcionamiento del aparato productivo, al servicio de los legitimos intereses nacionales.

A tal propósito, importa traer a colación el documento presentado por José Consuegra, Arturo Bonilla, Andre Gunder Frank y quien suscribe, en la reunión de facultades y Escuelas de Economía de América Latina, realizada en la ciudad de México, en junio de 1965, el cual recibió la aprobación de todas las delegaciones del continente:

Somos los economistas de América Latina los que tenemos la obligación de formular un cuerpo de conocimientos que sea el resultado de la observación, experiencia y estudio de nuestra realidad... Los principales obstáculos que frenan y deforman el desarrollo económico y social de América Latina, son de carácter estructural, $y$ están ligados a problemas internos y a la dependencia con respecto a los paises dominantes... Por eso consideramos imprescindible formular una teoría económica de América Latina, que, sin ignorar los aportes constructivos de otras regiones del mundo, surja esencialmente de la observación y análisis de nuestros problemas, y recoja los lineamientos de los objetivos por lograr.

\section{La globalización y la universidad}

De ese proceso de la globalización, no puede sustraerse -por supuesto- la universidad.

Conviene precisar, tratándose de un reconocimiento universitario, que el desafio de la universidad venezolana consiste en que ella debe crear, desarrollar y aplicar su propia estrategia para atender los problemas educacionales, sociales, culturales, económicos, ambientales, tecnológicos y científicos del país. La universidad debe estar al frente de las propuestas de cambio, de las auténticas transformaciones, no sólo para sí misma, como institución, sino para todo el país.

De los conflictos actuales, y aún de los que vendrán, no se puede evadir, por supuesto, la universidad venezolana, y por ello debe asumir la responsabilidad que le corresponda; pero es indudable que, dentro de la estrategia que se ha planificado para poner cercos a la institución, ha surgido e irá adquiriendo un énfasis cada vez mayor, un ánimo adverso hacia la universidad crítica y de contenido social, creativa y gratuita. Conceptos que hago míos, porque a la universidad -tal como lo siento- la defiendo y la defenderé mientras viva. 
Se pretende que la universidad asuma pasivamente el proceso de globalización transnacionalizador.

Los universitarios debemos admitir la necesidad de mejorar nuestro rendimiento. La universidad deberá colocarse al trente de las propuestas de cambios que incidan sobre la propia institución y el país. Hay necesidad de una mayor cooperación de las relaciones sociales que tienen lugar dentro de la estructura universitaria, con el objetivo de optimizar sus recursos y fortalecer su responsabilidad colectiva, tanto como su fuerza moral. Pero lo que no debemos admitir es que la ola de racionalidad que invade nuestras instituciones, nos obnubile, hasta el grado de ocasionar daños serios e irreparables a la institución, suscitando mayores desajustes y elevando el costo social en forma considerable.

En estos tiempos, cuando las principales investigaciones que se realizan tienen como propósito fundamental facilitar el avance de la globalización transnacionalizadora, es preciso desarrollar investigaciones científicas, dándoles un rango de carácter estratégico, con el propósito de evitar, en la medida de lo posible, ser barridos por los "gladiadores mundiales", y que nuestras patrias se conviertan en simples agentes propagadores transnacionalizados de la globalización.

Hoy, más que nunca, se necesita de un pensamiento propio $y$, fundamentalmente, latinoamericano. $Y$, en este sentido, la universidad venezolana tiene una gran responsabilidad histórica.

Ruego a todos ustedes me concedan evocar a mis padres (Salvador Parra y María Chiquinquirá Luzardo), quienes en medio de la pobreza, de la lucha por la subsistencia de la vida, lograron formarme con los principios de la dignidad humana, de la justicia, del profundo amor a mi país y de la vocación de servicio a los más nobles ideales, en los cuales creo y defiendo.

A Ligia, esposa y compañera desde siempre y para siempre, a mis hijas: Isabel, Ligia y Delfina; a mis hijos politicos, hermanos y sobrinos, y también a mis amigos y compañeros de vida, quienes tanta solidaridad humana y académica me han brindado desinteresadamente.

Por último, deseo concluir recordando el pensamiento de Miguel de Unamuno, que me ha acompañado durante toda mi existencia:

"Que nunca tu pasado sea tírano de tu porvenir". 